\title{
Degradation of Tris(1-chloro-2-propanyl) Phosphate by the Synergistic Effect of Persulfate and Zero- valent Iron During a Mechanochemical Process
}

Weichuan Qiao ( $\sim$ hgqwc@njfu.edu.cn )

Nanjing Forestry University https://orcid.org/0000-0001-9721-9364

Qiwen Yang

Nanjing Forestry University

Yi Qian

Nanjing Forestry University

Ziyan Zhang

Nanjing Forestry University

\section{Research Article}

Keywords: Tris(1-chloro-2-propanyl) phosphate, Persulfate, Mechanochemical, Zero-valent iron, Dechlorination, Degradation

Posted Date: August 13th, 2021

DOl: https://doi.org/10.21203/rs.3.rs-576669/v1

License: (9) This work is licensed under a Creative Commons Attribution 4.0 International License. Read Full License

Version of Record: A version of this preprint was published at Environmental Science and Pollution Research on January 17th, 2022. See the published version at https://doi.org/10.1007/s11356-02218665-6. 


\section{Degradation of tris(1-chloro-2-propanyl) phosphate}

2 by the synergistic effect of persulfate and zero-valent iron during a mechanochemical process

6 a Department of Environmental Engineering, College of Biology and the Environment,

$7 \quad$ Nanjing Forestry University, Nanjing 210037, China

8 b Nanjing Yi Wei Environmental Protection Technology Co., Ltd., Nanjing 210048,

9 China

10

11

12 * Corresponding authors. E-mail address: hgqwc@njfu.edu.cn (W. Qiao)

13

14 
This study revealed a dual pathway for the degradation of tris (1-chloro-2-propanyl)

17 phosphate (TCPP) by zero-valent iron (ZVI) and persulfate as co-milling agents in a mechanochemical (MC) process. Persulfate was activated with ZVI to degrade TCPP in a planetary ball mill. After milling for $2 \mathrm{~h}, 96.5 \%$ of the TCPP was degraded with the release of $63.16,50.39$ and $42.01 \%$ of the $\mathrm{Cl}^{-}, \mathrm{SO}_{4}{ }^{2-}$ and $\mathrm{PO}_{4}{ }^{3-}$, respectively. In the

21 first degradation pathway, persulfate was activated with ZVI to produce hydroxyl $(\cdot \mathrm{OH})$ radicals and ZVI is oxidized to $\mathrm{Fe}$ ( II ) and Fe(III). A substitution reaction occurred as a result of the attack of $\cdot \mathrm{OH}$ on the $\mathrm{P}-\mathrm{O}-\mathrm{C}$ bonds, leading to the successive breakage

24 of the three $\mathrm{P}-\mathrm{O}-\mathrm{C}$ bonds in TCPP to produce $\mathrm{PO}_{4}{ }^{3-}$. In the second pathway, a $\mathrm{C}-\mathrm{Cl}$ bond in part of the TCPP molecule was oxidized by $\mathrm{SO}_{4} \cdot{ }^{-}$to carbonyl and carboxyl groups. The $\mathrm{P}-\mathrm{O}-\mathrm{C}$ bonds continued to react with $\cdot \mathrm{OH}$ to produce $\mathrm{PO}_{4}{ }^{3-}$. Finally, the intermediate organochloride products were further reductively dechlorinated by ZVI. However, the synergistic effect of the oxidation $\left(\cdot \mathrm{OH}\right.$ and $\left.\mathrm{SO}_{4}{ }^{-}\right)$and the reduction reaction (ZVI) did not completely degrade TCPP to $\mathrm{CO}_{2}$, resulting in a low mineralization rate $(35.87 \%)$. Moreover, the intermediate products still showed the

31 toxicities in $\mathrm{LD}_{50}$ and developmental toxicant. In addition, the method was applied for

32 the degradation of TCPP in soil, and high degradations $(>83.83 \%)$ were achieved in 33 different types of soils. 
37 Speciality: Phosphorus flame retardants; Advanced oxidation process; Ball milling 


\section{Introduction}

Brominated flame retardants (BFRs) have been banned in Europe on the grounds of their toxicity (Veen \& Boer, 2012). They have been replaced by phosphorus flame retardants (PFRs), which are used to prevent the spread of flames after combustion and to delay ignition. PFRs are widely used in the textile and electronics industries, in transportation and in home improvement materials (Veen \& Boer, 2012). However, PFRs can be released to the environment via volatilization, product wear and leakage during production and use. Although PFRs are not listed as persistent organic pollutants (POPs), they are long-lived in the environment (Quintana et al., 2008). As a typical PFRs, tris(1-chloro-2-propanyl) phosphate (TCPP) has a potential toxicity which is similar with BFRs (Björklund et al., 2004). Thus, TCPP should be removed from the environment as a matter of urgency.

TCPP has been detected in water, air, soil and organisms (Un-Jung et al., 2017, Wang et al., 2017). The levels of TCPP in surface water range from $0.05 \mu \mathrm{g} / \mathrm{L}$ to 10 $\mu \mathrm{g} / \mathrm{L}$, and those in river sediments were up to $165 \mu \mathrm{g} / \mathrm{kg} \mathrm{dw}$. Previous reports have shown that TCPP is both carcinogenic and teratogenic and accumulates in the liver and kidneys, resulting in a decrease of the number of cells and a change in neurotransmitters (Hoffman et al., 2014). Mechanochemical (MC) destruction is an effective and environmentally friendly method of removing chlorinated organic pollutants (Yan et al., 2017). Unlike photocatalytic and microbial degradation (Jurgens et al., 2014, Ruan et al., 2013), MC degradation is inexpensive, rapid, efficient, produces harmless 
61 persistent organic pollutants (Veen \& Boer, 2012). However, the MC degradation of TCPP has not been reported previously. in a ball-milling reactor and the bonds in the target pollutants are destroyed as a result of the change in the morphology and crystal structure of the pollutant (Dubinskaya, 2010). TCPP contains $\mathrm{P}-\mathrm{O}-\mathrm{C}$ and $\mathrm{C}-\mathrm{Cl}$ bonds, which both have important roles in maintaining the stability and toxicity of POPs. However, the use of MC processes to simultaneously degrade pollutants containing both phosphorus and chlorine has not been reported previously. We suggest that the mechanisms of the MC degradation of TCPP are different from those of other POPs. Metals and metal oxides have been used as co-milling reagents to enhance the efficiency of the MC process in ball-milling (Fan et al., 2018, Yan et al., 2017). As a strong oxide, persulfate is widely used in the degradation of organic matter. It can be activated by heat, alkalis, ultraviolet light, microwave irradiation and transition metals to form highly active sulfate radicals $\left(\mathrm{SO}_{4} \cdot^{-}\right)$that react with organic molecules (Oh et al., 2009, Wei et al., 2016). Also, persulfate can be activated by $\mathrm{MC}$ process with $\mathrm{NaOH}$ or $\mathrm{CaO}$ to degrade organic pollutants (Fan et al., 2020, Yan et al., 2015). Previous studies have shown that zero-valent iron (ZVI), $\mathrm{Fe}^{2+}$ and $\mathrm{Fe}^{3+}$ can activate persulfate (Oh et al., 2009, Wei et al., 2016, Yan et al., 2017). Under the action of free radicals, the $\mathrm{C}-\mathrm{Cl}$ bonds of organic pollutants are broken and organic substances gradually 
81 become inorganic substances, eventually resulting in mineralization (Cagnetta et al., 82 2017). In the MC process, zero-valent metals or metal oxides have been used as co83 milling reagents with persulfate to enhance the MC degradation of pollutants (Liu et al., 84 2016a, Wang et al., 2019). However, the degradation of chlorinated organic compounds 85 via a MC process with both ZVI and persulfate as co-milling agents has not yet been reported, and the degradation mechanisms remain unclear. Especially, the synergistic effect of the reduction of ZVI and the oxidation reaction of $\mathrm{SO}_{4} \cdot{ }^{-}$in $\mathrm{MC}$ process on pollutants degradation need to be further explored. ZVI and persulfate were used as co-milling reagents to remove TCPP in a planetary ball mill. The objectives of this study were to reveal the mechanism by which

91 a persulfate $+\mathrm{Fe}+$ mechanochemical $\left(\mathrm{PS}+\mathrm{Fe}^{0}+\mathrm{MC}\right)$ process can use activated persulfate to degrade TCPP. The degradation intermediates and final products of TCPP were to be identified. The aim was to determine the pathway for the degradation of TCPP by this MC method to develop a new method for the remediation of chlorinated organic compounds.

\section{Materials and methods}

\subsection{Materials}

99 Technology Development (Shanghai, China). This product contains two isomers (Fig.

100 S1 and Table S1): tri(chloro-isopropyl) phosphate and bis-(1-chloro-2-propyl) (3-

101 chloro-1-propyl) phosphate, referred to here as TCPP 1 and TCPP 2 , respectively. Iron 
103 China). Potassium persulphate $\left(\mathrm{K}_{2} \mathrm{~S}_{2} \mathrm{O}_{8}, \geq 98 \%\right.$ purity) and the solvents (methanol, ethyl

104 acetate and absolute ethanol) used in the gas chromatography-mass spectrometry (GC-

105 MS) analyses were all purchased from Sinopharm Chemical Reagent (Shanghai, China).

106 Ethyl acetate was purchased from Sinopharm Chemical Reagent Co., Ltd., Shanghai,

107 China. All other chemical reagents and organic solvents were of analytical-reagent 108 grade.

109 Three soils were collected from Liaoning (red soil), Jiangsu (yellow soil) and

110 Heilongjiang (black soil) in China, respectively. All the soils were air-dried for one

111 week ground and passed through a 1-mm mesh screen. The selected soil was stored at

$1124{ }^{\circ} \mathrm{C}$ and used as natural soil.

\section{2.2. Ball-milling experiment}

114 The MC experiment was performed in a planetary ball mill (QM-1SP2, Nanjing

115 University Instrument Corp., Nanjing, China). Different ratios of iron powder and

116 persulfate were mixed with the TCPP as co-milling reagents to give different weight

117 ratios. The $\mathrm{Fe}^{0}+$ persulfate+TCPP mixture weighed $5 \mathrm{~g}$. $150 \mathrm{~g}$ of stainless-steel balls

118 with diameters of 5 and $8 \mathrm{~mm}$ were placed into two $500-\mathrm{mL}$ stainless-steel pots. The

119 planetary ball mill was operated at a speed of 300 500 rev $\mathrm{min}^{-1}$ and the direction of

120 rotation changed automatically every $45 \mathrm{~min}$, including a $15 \mathrm{~min}$ pause for cooling. All 
121 the experiments were performed in triplicate. The values of the mean and standard

122 deviation were calculated by SPSS 19.0 software.

\subsection{MC degradation of TCPP in soil} cooling time. All experiments were performed in triplicate.

\subsection{Determination of TCPP and the degradation product}

131 each ground sample was extracted with $10 \mathrm{~mL}$ of ethyl acetate and concentrated to 1

$132 \mathrm{~mL}$ in a rotary evaporator (Rotavapor R-200, Buchi, Flawil, Switzerland) (Liu et al.,

133 2016b). The concentration of TCPP was determined by GC/MS/MS using an Agilent

134 7000B system equipped with a DB-1 column $(30 \mathrm{~m} \times 0.25 \mathrm{~mm} \times 1.00 \mu \mathrm{m})$ (Agilent

135 Technologies Inc., USA). The column temperature was increased from 60 to $280^{\circ} \mathrm{C}$

136 (held for $1 \mathrm{~min}$ ) at $15^{\circ} \mathrm{C} \mathrm{min}^{-1}$ and the residence time of the solvent was $5 \mathrm{~min}$. The

137 carrier gas was $99.999 \%$ He. The mass spectrometer transmission line and the ion

138 source temperature were both $250^{\circ} \mathrm{C}$ and the mass scan range was $30 \sim 400$.

139 The degradation products of TCPP were qualitatively determined by liquid 140 chromatography-quadrupole time-of-flight mass spectrometry (LC-QTOF-MS) using 
141 a Shimadzu LC $30 \mathrm{~A}+\mathrm{AB}$ Sciex Triple TOF $5600^{+}$system equipped with a Agilent

142 ZORBAX SB-C18 column $(100 \mathrm{~mm} \times 2.1 \mathrm{~mm} \times 3.5 \mu \mathrm{m})$. The column temperature was

$14340^{\circ} \mathrm{C}$. The measurements were performed in the positive ion mode by gradient elution

144 using water (containing $0.1 \%$ formic acid) and acetonitrile at a flow-rate of $0.3 \mathrm{~mL} / \mathrm{min}$.

145 The mass scan range was 50 1000 (Yu et al., 2019).

146 2.5. Determination of $\mathrm{Cl}^{-}, \mathrm{SO}_{4}{ }^{2-}$ and $\mathrm{PO}_{4}{ }^{3-}$

147 After MC treatment, $0.01 \mathrm{~g}$ of each sample was dissolved in $20 \mathrm{~mL}$ of Milli-Q

148 water. The mixture was stirred with a magnetic stirrer for $20 \mathrm{~min}$ at $80^{\circ} \mathrm{C}$ and then

149 treated ultrasonically for $30 \mathrm{~min}$ before filtration through a $0.47 \mu \mathrm{m}$ fiber filter (Zhang

150 et al., 2011). $\mathrm{Cl}^{-}, \mathrm{SO}_{4}{ }^{2-}$ and $\mathrm{PO}_{4}{ }^{3-}$ were determined in the collected filtrate using an

151 ICS900 ion chromatography system (Dionex, USA) equipped with a IonPac AG23

152 Guard Column $(4 \times 50 \mathrm{~mm})$. The column temperature was $25^{\circ} \mathrm{C}$ with a flow-rate of 1

$153 \mathrm{~mL} / \mathrm{min}$ and current intensity of the anion was $35 \mathrm{~mA}$. The change in ion concentration

154 was calculated by the release rate:

155

Release rate $=\left(C_{\mathrm{t}}-C_{0}\right) / C_{0}$

156 where $C_{\mathrm{t}}$ is the concentration of the ion at $t(\mathrm{~min})$ and $C_{0}$ is the concentration of the

157 ion at $0 \mathrm{~min}$.

158

\subsection{Instrumental analysis}

159 Different methods of analysis were used to characterize the ball-milling samples

160 collected at different times in the ball-milling experiment to clarify the mechanism of

161 TCPP degradation by the MC process. Raman spectra were recorded using a DXR532 
163 laser beam at $514.5 \mathrm{~nm}$ and a scan range of $400 \sim 2500 \mathrm{~cm}^{-1}$ (Liu et al., 2016b). The

164 infrared spectra were measured with the $\mathrm{KBr}$ disk method using a Thermo Fisher

165 Scientific Nicolet IS5 Fourier transform infrared (FTIR) spectrometer in the range $166400 \sim 4000 \mathrm{~cm}^{-1}$ (Dong et al., 2019).

167 The crystal structure of the ball-milling sample was analyzed with an Ultima IV 168 X-ray diffraction (XRD) spectrometer (Rigaku Electric Co., Ltd, Japan) in the range $2 \theta$ $169=10 \sim 90^{\circ}$ at a step size of $0.02^{\circ}$ (Sui et al., 2017). The elemental distribution and micro170 morphology of the ball-milling samples were analyzed by field-emission scanning 171 electron microscopy using an FEI Quanta 400 FEG (Quanta, USA). The changes in the

172 valence states of the elements in the ball-milling samples were analyzed by X-ray 173 photoelectron spectrometry (XPS) using a ESCALAB 250Xi spectrometer (Thermo

174 Fisher Scientific, USA) and the binding energy scale was calibrated by the C1s peak at $175284.8 \mathrm{eV}$ (Dong et al., 2019). The active species and free radical were determined by 176 an electron spin resonance (ESR) using Bruker ESR A320 (Germany).

\section{$177 \quad$ 2.7. Statistical analysis}

178 All the data were mean \pm standard deviation values from three different 179 experiments obtained in triplicate. An analysis of variance (ANOVA) was used to test 180 the significance of the results using SPSS 19.0 software and $p<0.05$ was considered 181 to be statistically significant. 


\section{Results and discussion}

183

184

185

186

187

188

189

190

191 efficiency of TCPP increased as the material ratio increased when the ratio of ZVI to

192 persulfate was $4: 1$. When the material ratio reached 20:1 and 30:1, the degradation

193 efficiencies of TCPP 1 and TCPP 2 were $>90 \%$ after ball-milling for $2 \mathrm{~h}$. When the

194 material ratio was 30:1, the degradation efficiencies of TCPP 1 and TCPP 2 were as

195 high as 97.10 and $98.17 \%$, respectively. However, when the material ratio was 10:1, the

196 degradation efficiencies of TCPP 1 and TCPP 2 were only 77.76 and $70.01 \%$,

197 respectively. These results show that as the material ratio increases, an increase in the

198 ZVI and persulfate content increases the degradation efficiency of TCPP. ZVI provides

199 electrons during the ball-milling process, which activate persulfate to generate free

200 radicals, which, in turn, attack the chlorine atoms in pollutants and accelerate the 201 process of dechlorination . 
(a)

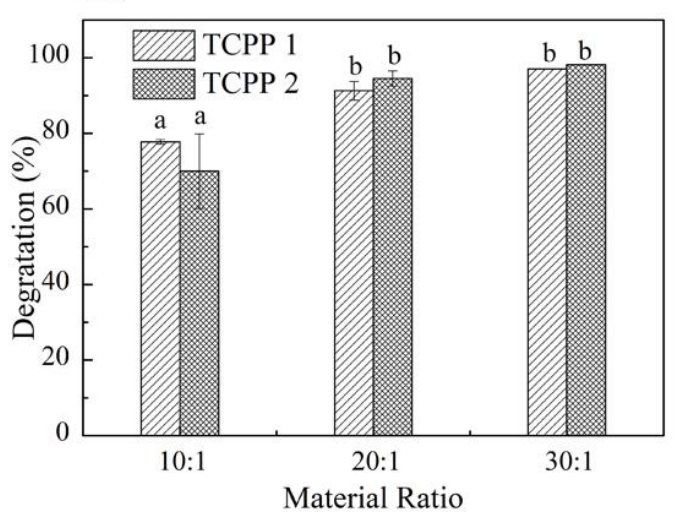

(c)

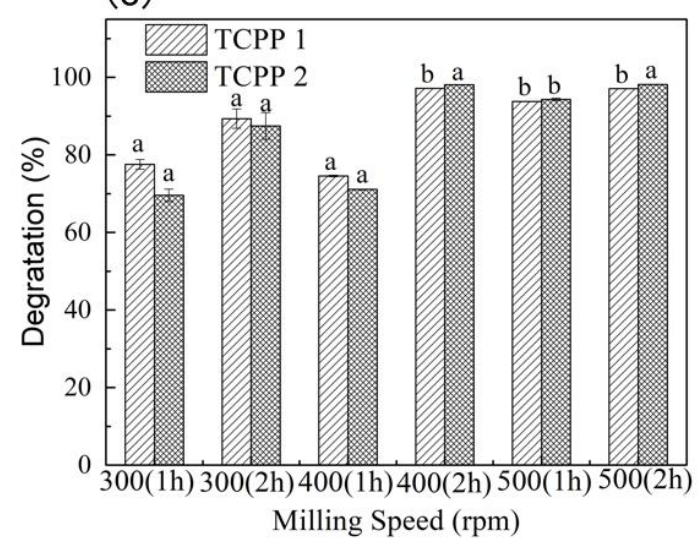

(b)

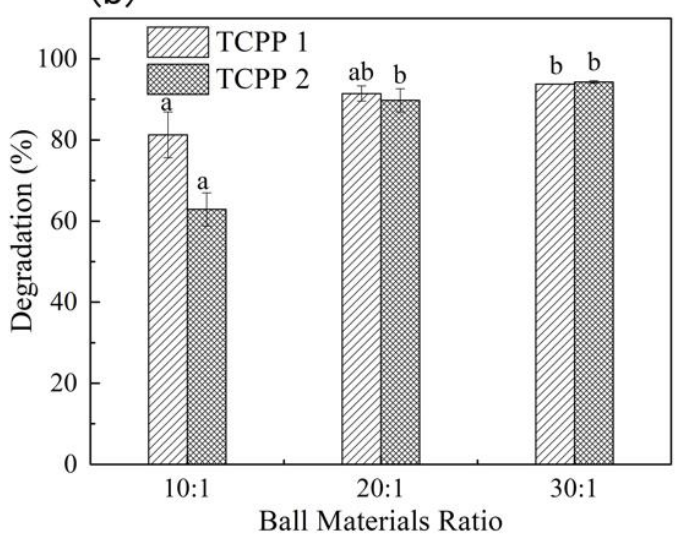

(d)

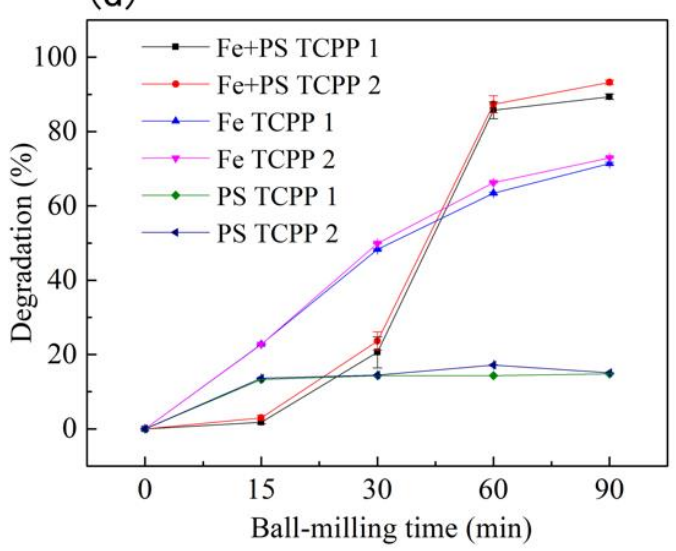

203 Fig. 1. Degradation efficiency of TCPP by the PS $+\mathrm{Fe}^{0}+\mathrm{MC}$ process under different (a)

204 material ratios (ratio of ZVI and persulfate 4:1, with ball-milling for $2 \mathrm{~h}$ ), (b) ball to material ratios and (c) milling speeds. (d) Comparison with different co-milling reagents. Different letters indicate a significant difference at $p<0.05$

$209(10: 1,20: 1$ and 30:1) were selected. Fig. 1b shows that the efficiencies of the MC

210 degradation of TCPP increased with an increase in the BMR. When the BMR was 30:1,

211 the degradation efficiencies of TCPP 1 and TCPP 2 were 93.78 and $94.30 \%$, 212 respectively, but the degradation efficiencies of TCPP 1 and TCPP 2 were only 81.24 
213 and $62.87 \%$ when the BMR was 10:1. This is because the collision energy increases as

214 the mass of the milling balls increases, which favors the degradation of pollutants. The

215 removal of pollutants is also related to the collision power. The collision power includes

216 the collision energy and the collision frequency (Abdellaoui \& Gaffet, 1995). The

217 collision frequency in the ball mill tank increases as the number of milling balls

218 increases. However, too many milling balls reduce the space available for the

219 movement of balls in the ball-milling tank, which decreases both the collision speed

220 and energy (Sui et al., 2017).

221 Fig. 1c shows the effect of milling speed on the degradation of TCPP and indicates

222 that the degradation efficiency increases with an increase in the milling speed. The

223 degradation efficiencies of TCPP 1 and TCPP 2 reached 93.79 and $94.30 \%$, respectively,

224 after $1 \mathrm{~h}$ of milling time at $500 \mathrm{rev} \mathrm{min}^{-1}$. The kinetic energy in a planetary ball mill is

225 transferred during the ball-milling process and the speed determines the total energy

226 input from the ball mill (Abdellaoui \& Gaffet, 1995). As the rotation speed increases,

227 the collision speed and frequency of the milling ball and the target pollutant increase,

228 which results in a high mechanical energy of the mixture in the tank, thereby converting

229 it into chemical energy. The MC reaction is therefore accelerated, resulting in the rapid

230 degradation of the pollutant . The removal efficiency of TCPP was $>97 \%$ at 400 and

$231500 \mathrm{rev} \min ^{-1}$ after $2 \mathrm{~h}$ of milling time.

232 Fig. 1d shows the degradation of $0.16 \mathrm{~g}$ TCPP with persulfate, ZVI or a mixture

233 of ZVI and persulfate as the co-milling regents (4.84 g). After milling for $2 \mathrm{~h}$, the 
234 degradation efficiencies of TCPP 1 were $20.21,80.15$ and $95.50 \%$ in the $\mathrm{MC}+$ persulfate 235 (MC+PS), $\mathrm{MC}+\mathrm{Fe}^{0}$ and $\mathrm{PS}+\mathrm{Fe}^{0}+\mathrm{MC}$ experiments, respectively. The degradation 236 efficiencies of TCPP 2 were $20.21,75.93$ and $96.50 \%$ in the $\mathrm{MC}+\mathrm{PS}, \mathrm{MC}+\mathrm{Fe}^{0}$ and $237 \mathrm{PS}+\mathrm{Fe}^{0}+\mathrm{MC}$ experiments, respectively. The degradation efficiency of TCPP did not 238 change when persulfate alone was used as the co-milling reagent. The degradation 239 efficiency increased with an increase in the milling time for the $\mathrm{Fe}^{0}+\mathrm{MC}$ and the $240 \mathrm{PS}+\mathrm{Fe}^{0}+\mathrm{MC}$ systems. After 45 min of ball-milling, the $\mathrm{PS}+\mathrm{Fe}^{0}+\mathrm{MC}$ system had the 241 highest degradation efficiency of TCPP.

242 A combination of ZVI and persulfate has been used previously as an advanced 243 oxidation method to remove organic pollutants from water (Oh et al., 2009, Wei et al., 244 2016). As a strong oxidant, persulfate can be activated by ultraviolet light, heating or 245 transition metals to generate sulfate radicals that can oxidize and decompose pollutants.

246 Metals can produce lattice defects after ball-milling and then generate a large number 247 of electrons, which favors electron transfer in the dechlorination process (Cagnetta et 248 al., 2017). Therefore the $\mathrm{Fe}^{2+}$ produced by the electron transfer of ZVI can activate 249 persulfate to generate $\mathrm{SO}_{4} \cdot{ }^{-}$to promote the removal of TCPP.

250 The particle shape and size of the co-milling agents also can affect the efficiency 251 of the degradation of pollutants. In this study, small particles were adsorbed onto the 252 surface of large particles and large agglomerates formed, suggesting that the large 253 particles would break and form a new surface after ball-milling (Fig. S3). The particle 254 size of the co-milling agents decreased with increasing milling time (Fig. S4). After 
256 min, particles $>45 \mu \mathrm{m}$ disappeared completely, showing that the degradation of TCPP

257 continued over time (Wang et al., 2020). The smaller the particle size and the larger the 258 specific surface area of ZVI, the stronger the reaction activity. Small size was beneficial 259 for ZVI to stimulate PS to produce $\mathrm{SO}_{4} \cdot^{-}$and reduce organic pollutants

260 3.2. Dechlorination and mineralization of TCPP

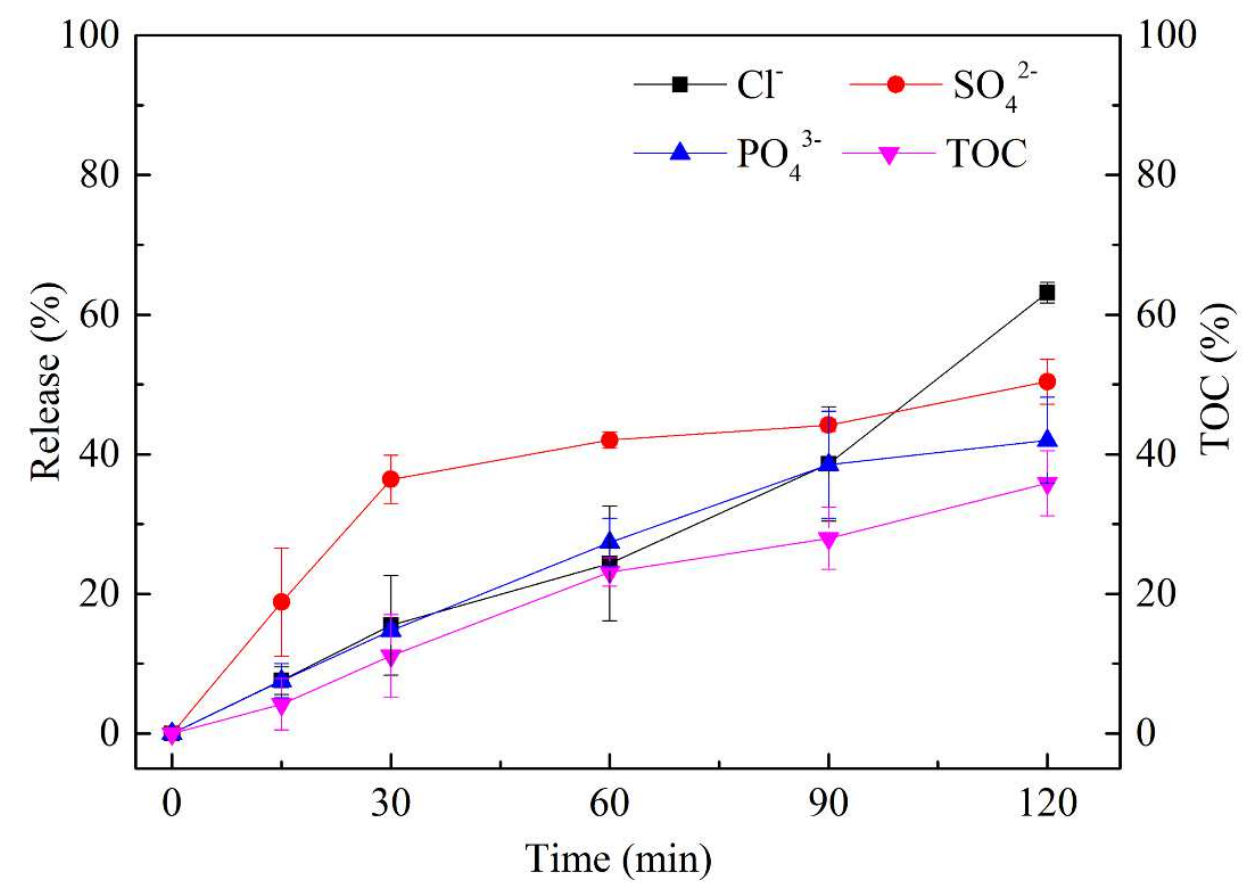

Fig. 2. Ion release rate and removal rate of total organic carbon from ball-milled samples at different times

The molecular structure of TCPP contains a phosphoric acid center and three 266 chlorinated alkyl chains. When the free radicals generated during the ball-milling 267 process attack the TCPP molecule, $\mathrm{Cl}^{-}$and $\mathrm{PO}_{4}{ }^{3-}$ are released and $\mathrm{S}_{2} \mathrm{O}_{8}{ }^{2-}$ is converted 
to $\mathrm{SO}_{4}{ }^{2-}$. Fig. 2 shows that the release efficiencies of $\mathrm{Cl}^{-}, \mathrm{SO}_{4}{ }^{2-}$ and $\mathrm{PO}_{4}{ }^{3-}$ increased as

269 the ball-milling time increased. The release of $\mathrm{SO}_{4}{ }^{2-}$ was higher than that $\mathrm{Cf}^{-}$and

$270 \mathrm{PO}_{4}{ }^{3-}$ until a milling time of $90 \mathrm{~min}$. After ball-milling for $2 \mathrm{~h}$, the release efficiencies

271 of $\mathrm{Cl}^{-}, \mathrm{SO}_{4}{ }^{2-}$ and $\mathrm{PO}_{4}{ }^{3-}$ were $63.16,50.39$ and $42.01 \%$, respectively.

272 TCPP can be dechlorinated to phosphorus-containing organic species, the organic

273 group of which is removed to produce $\mathrm{PO}_{4}{ }^{3-}$. In addition, $\mathrm{PO}_{4}{ }^{3-}$ is not completely

274 released, indicating that the phosphoric acid center of TCPP is difficult to destroy

275 completely. When compared with the high degradation efficiency of TCPP, the

276 dechlorination of TCPP is not complete, which indicates that a large number of

277 chlorine-containing degradation intermediates are produced during the MC degradation

278 of TCPP. Fig. 2 also shows that the removal efficiency of total organic carbon only

279 reaches $35.87 \%$, indicating that TCPP is not completely mineralized, consistent with

280 the results of Liu et al. (2017).

281 3.3. Characterization of milled samples

282 
(a)

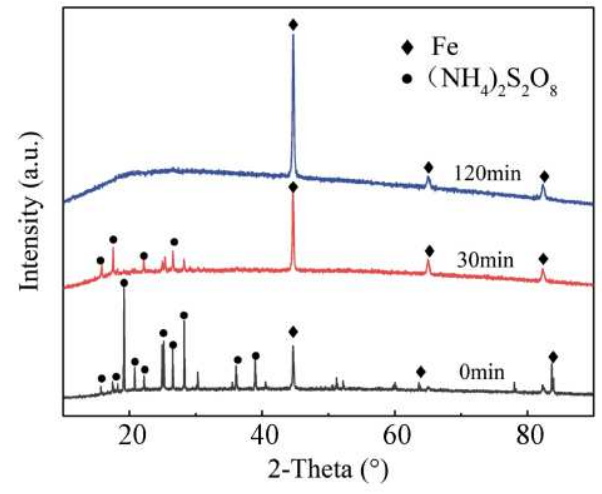

(c)

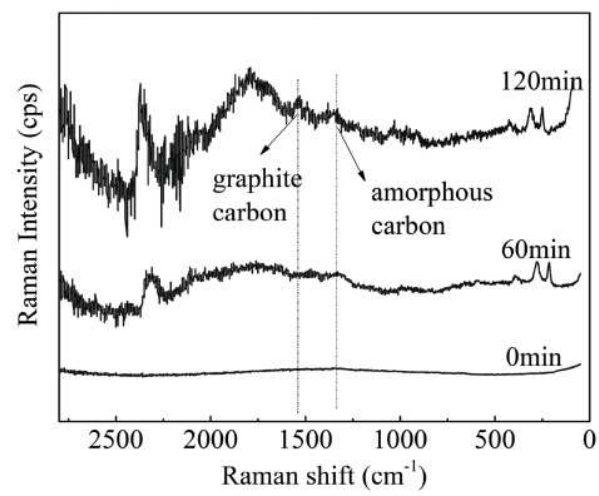

(b)

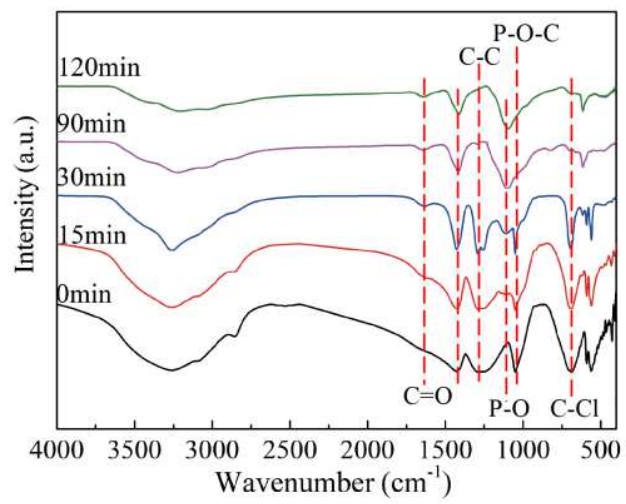

(d)

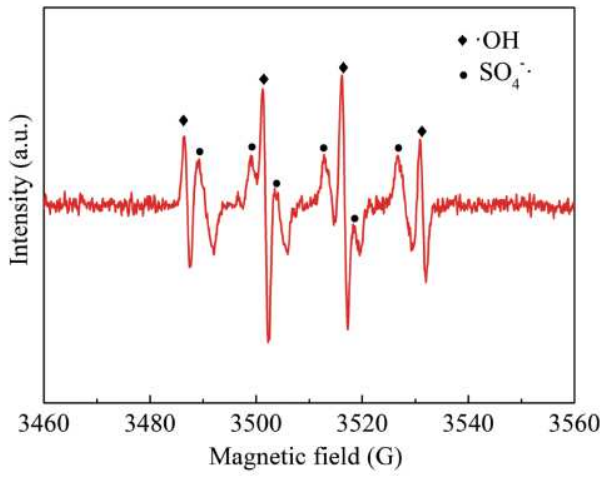

Fig. 3. (a) XRD, (b) FTIR, (c) Raman spectra of the ball-milled samples at different times and (d) the electron spin resonance spectra of samples ball-milled for $0.5 \mathrm{~h}$.

FTIR, XRD and Raman analyses were carried out on the ball-milled samples to TCPP molecules during ball-milling (Table S1).

Fig. 3a shows the XRD spectra of the milled samples for different milling times.

292 After milling for $30 \mathrm{~min}$, the characteristic peak for persulfate weakened, indicating that the $\mathrm{PS}+\mathrm{Fe}^{0}+\mathrm{MC}$ process rapidly destroyed TCPP. After milling for $2 \mathrm{~h}$, the Fe peak was greatly increased and the persulfate peak completely disappeared, indicating that 
295 the increased crystallinity of Fe activated persulfate, which has a major role in the 296 degradation of TCPP in the ball-milling process. In addition, the Fe peak was broadened 297 with the increasing milling time, indicating that the distortion of Fe lattice increased, 298 which provided more free electrons for the redox process in the degradation of TCPP 299 (Sui et al., 2017).

300 Fig. $3 \mathrm{~b}$ shows that the $\mathrm{C}-\mathrm{Cl}$ peak at $695 \mathrm{~cm}^{-1}$ decreased with an increase in the 301 ball-milling time, indicating that the $\mathrm{Cl}$ atom in TCPP was gradually removed to form $302 \mathrm{Cl}^{-}$. The peaks at 1049,1281 and $1428 \mathrm{~cm}^{-1}$, which represent the $\mathrm{P}-\mathrm{O}-\mathrm{C}$ and $\mathrm{C}-\mathrm{C}$ 303 bonds and the $\mathrm{CH}_{2}$ group, respectively, decreased with an increase in the milling time 304 (Yan et al., 2017, Zhang et al., 2020), which shows that the chloropropane group linked 305 to the ether bond was removed from TCPP. The fracture of the $\mathrm{C}-\mathrm{C}$ bond means that 306 the chloropropane side-chain was broken down to form smaller molecules. The peaks 307 at about $1100 \mathrm{~cm}^{-1}$, characteristic of the $\mathrm{P}-\mathrm{O}$ bond, increased after ball-milling (Siow 308 et al., 2014), which indicates that the number of phosphoric acid groups increased. The 309 peak at $1642 \mathrm{~cm}^{-1}$ related to the $\mathrm{C}=\mathrm{O}$ bond appeared during ball-milling, which means 310 that carbonyl groups formed in the product.

311 As the milling time increased, the color of the MC degradation product deepened 312 and the product turned completely black after milling for $2 \mathrm{~h}$ (Fig. S5), suggesting that 313 the samples were carbonized, which was confirmed by the Raman spectra (Fig. 3c).

314 The peak of the initial TCPP was unclear after $1 \mathrm{~h}$ of ball-milling. After milling for $2 \mathrm{~h}$, 315 two peaks at appeared at the D-band $\left(1330 \sim 1380 \mathrm{~cm}^{-1}\right)$ and the G-band $(1540 \sim 1580$ 
$316 \mathrm{~cm}^{-1}$ ), which correspond to the typical Raman spectra of amorphous carbon and

317 graphite, respectively (Wakayama et al., 1999). The appearance of the D and G peaks

318 in the Raman spectra suggests that TCPP was carbonized to carbon materials with

319 defective and disordered structures (Xu et al., 2013). The sequence of peaks D and G

320 showed that the carbonization process first generated amorphous carbon and then part

321 of the carbon product was converted to graphite. Zhang et al. (2011) reported that

322 pentachloronitrobenzene can be converted to amorphous carbon and graphite during

323 milling with Fe. The intensity of the D and $G$ peaks was not high, which showed that

324 only part of the TCPP was mineralized through carbonization. This shows that it is

325 difficult to fully mineralized TCPP and that mineralization was not the only pathway

326 used to degrade TCPP.

327 ESR was used to identify the active species in the PS $+\mathrm{Fe}^{0}+\mathrm{MC}$ system for selected

328 samples ball-milled for $30 \mathrm{~min}$. Fig. $3 \mathrm{~d}$ shows that the characteristic peaks of $\cdot \mathrm{OH}$ and

$329 \mathrm{SO}_{4} \cdot{ }^{-}$appeared, indicating that $\cdot \mathrm{OH}$ and $\mathrm{SO}_{4} \cdot{ }^{-}$were produced during the ball-milling

330 process(Yin et al., 2020). This result confirmed that the degradation of TCPP by the

$331 \mathrm{MC}$ process was a result of oxidation by $\cdot \mathrm{OH}$ and $\mathrm{SO}_{4}{ }^{-}$. 

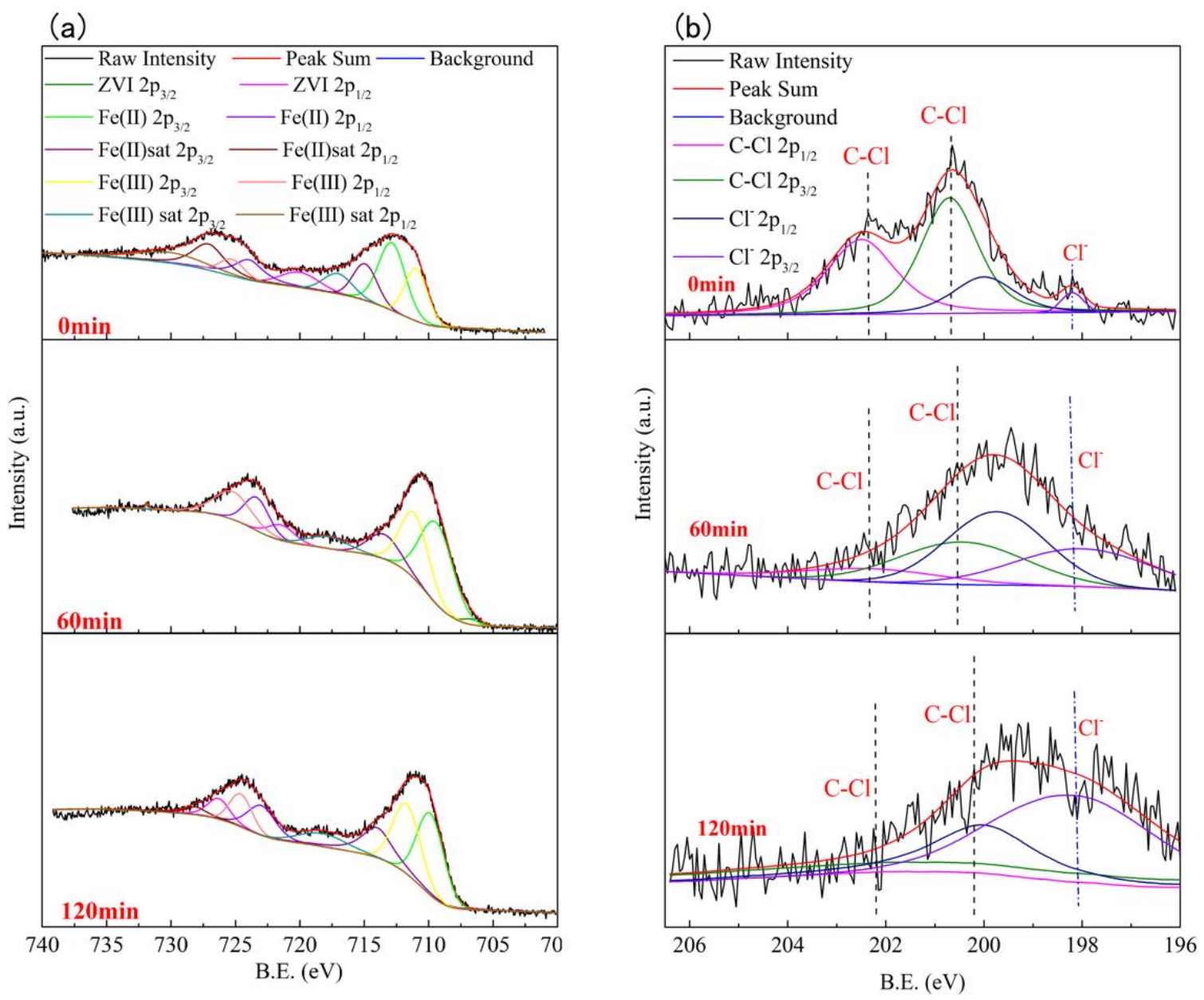

334 Fig. 4. XPS spectra of (a) Fe 2p and (b) $\mathrm{Cl} 2 \mathrm{p}$ of ball-milled samples at different times

XPS was used to analyze the chemical composition and changes in the valence of

337 the elements on the surface of the sample to investigate the degradation mechanism of

338 TCPP. All the XPS peaks were calibrated using the C1s peak at $284.8 \mathrm{eV}$. Table S2 gives

339 the specific binding energy positions of the fitted peaks of ZVI in the initial sample

340 (Deng et al., 2020). The changes in the peak areas of samples $\mathrm{Fe}^{0}, \mathrm{Fe}^{2+}$ and $\mathrm{Fe}^{3+}$ at

341 different milling times were compared.

342 Fig. 4a shows that the peak area of ZVI decreased with an increase in the milling 
343 time, whereas the peak areas of $\mathrm{Fe}^{2+}$ and $\mathrm{Fe}^{3+}$ increased. This suggests that ZVI was

344 oxidized to $\mathrm{Fe}^{2+}$ by persulfate during the ball-milling process with the formation of $345 \mathrm{SO}_{4}{ }^{2-}$ (Eq. (1)) (Al-Shamsi \& Thomson, 2013). Some of the $\mathrm{Fe}^{2+}$ was oxidized further 346 to $\mathrm{Fe}^{3+}$. The persulfate $\left(\mathrm{S}_{2} \mathrm{O}_{8}{ }^{2-}\right)$ was converted into $\mathrm{SO}_{4}{ }^{2-}$ and $\mathrm{SO}_{4}{ }^{-}$(Eq. (2)) (Oh et al., 347 2009). Some of the $\mathrm{Fe}^{2+}$ reacted with the sulfate radicals generated in Eq. (2) to produce $348 \mathrm{Fe}^{3+}$ and $\mathrm{SO}_{4}{ }^{2-}$ (Eq. (3)) (Kishi \& Ikeda, 1973). However, as shown in Fig. S6, the 349 concentration of the produced $\mathrm{Fe}^{2+}$ was far higher than that of $\mathrm{Fe}^{3+}$, showing $\mathrm{Fe}^{3+}$ is 350 easy to be reduced to $\mathrm{Fe}^{2+}$ in $\mathrm{MC}$ process (Eq.(5)). The results shows that the 351 degradation of TCPP by the $\mathrm{PS}+\mathrm{Fe}^{0}+\mathrm{MC}$ process was accompanied by the generation 352 of $\mathrm{SO}_{4}{ }^{2-}$, consistent with the increase in the release rate of $\mathrm{SO}_{4}{ }^{2-}$ shown in Fig. 2 (Deng 353 et al., 2020). The $\mathrm{SO}_{4}^{-}$generated in Eq. (2) reacted with water (present in humid air and 354 in additives) to generate hydroxyl radicals $(\cdot \mathrm{OH})$ and $\mathrm{SO}_{4} \cdot{ }^{-}$(Eq. (4)). These results all 355 confirm that persulfate can be activated by ZVI to generate $\mathrm{SO}_{4} \cdot^{-}$and $\cdot \mathrm{OH}$ radicals, 356 thereby promoting the degradation of TCPP. Finally, the reduction reaction of ZVI 357 could remove chlorine in the micromolecular chlorinated organics which were the 358 intermediate products during the MC process (Eq. (6)).

$$
\mathrm{Fe}^{0}+\mathrm{S}_{2} \mathrm{O}_{8}{ }^{2-} \rightarrow \mathrm{Fe}^{2+}+2 \mathrm{SO}_{4}^{2-}
$$

$$
\mathrm{Fe}^{2+}+\mathrm{S}_{2} \mathrm{O}_{8}{ }^{2-} \rightarrow \mathrm{Fe}^{3+}+\mathrm{SO}_{4}{ }^{--}+\mathrm{SO}_{4}{ }^{2-}
$$

$$
\mathrm{Fe}^{2+}+\mathrm{SO}_{4} \cdot{ }^{-} \rightarrow \mathrm{Fe}^{3+}+\mathrm{SO}_{4}^{2-}
$$

$$
\mathrm{H}_{2} \mathrm{O}+\mathrm{SO}_{4} \cdot{ }^{-} \rightarrow \cdot \mathrm{OH}+\mathrm{SO}_{4}{ }^{2-}+\mathrm{H}^{+}
$$


Fig. $4 \mathrm{~b}$ shows the change in valency of chlorine. In the initial stage, the

367 characteristic peaks of the $\mathrm{C}-\mathrm{Cl}$ bond appeared at about 200.7 and $202.5 \mathrm{eV}$ and a weak

$368 \mathrm{Cl}^{-}$peak was seen at about $198.2 \mathrm{eV}$ (Moulder et al., 1992). After ball-milling for $1 \mathrm{~h}$,

369 the characteristic peak of the $\mathrm{C}-\mathrm{Cl}$ bond gradually weakened until it disappeared at $2 \mathrm{~h}$,

370 whereas the characteristic peak of $\mathrm{Cl}^{-}$gradually strengthened. This shows that TCPP 371 was destroyed and the organic chlorine in the TCPP molecule was transformed into 372 inorganic chlorine.

\subsection{Degradation pathways of TCPP in $\mathrm{PS}+\mathrm{Fe}^{0}+\mathrm{MC}$ treatment}

The degradation products of TCPP1 were analyzed by LC-QTOF-MS and five

376 intermediate products were detected: $\mathrm{C}_{6} \mathrm{H}_{13} \mathrm{Cl}_{2} \mathrm{O}_{4} \mathrm{P}$ (product $\mathrm{A}, m / z 251.0$ ); $\mathrm{C}_{3} \mathrm{H}_{8} \mathrm{ClO}_{4} \mathrm{P}$

377 (product $\mathrm{B}, m / z$ 175.0); $\mathrm{C}_{9} \mathrm{H}_{17} \mathrm{Cl}_{2} \mathrm{O}_{5} \mathrm{P}$ (product $\mathrm{C}, m / z$ 307.0); $\mathrm{C}_{9} \mathrm{H}_{17} \mathrm{Cl}_{2} \mathrm{O}_{6} \mathrm{P}$ (product $\mathrm{D}$, $378 m / z$ 323.0) and $\mathrm{C}_{6} \mathrm{H}_{12} \mathrm{Cl}_{2} \mathrm{O}_{6} \mathrm{P}$ (product $\mathrm{E}, \mathrm{m} / z$ 247.0). Table $\mathrm{S} 7$ shows the corresponding 379 information and mass spectra.

380 Two degradation pathways of TCPP are proposed (Fig. 5). The first pathway is the 381 P-O-C cleavage pathway, which is similar to the oxidative degradation of organic 382 phosphorus compounds (Cheng et al., 2020). The $\cdot \mathrm{OH}$ generated by the activation of 383 persulfate attacks the phosphate center of TCPP and TCPP is cleaved at the $\mathrm{P}-\mathrm{O}-\mathrm{C}$ 384 bond to form the hydroxylated product A and 1-chloropropane . Product A is oxidized 
385 by the same process to form product $\mathrm{B}$, producing a third 1-chloropropane and $\mathrm{PO}_{4}{ }^{3-}$.

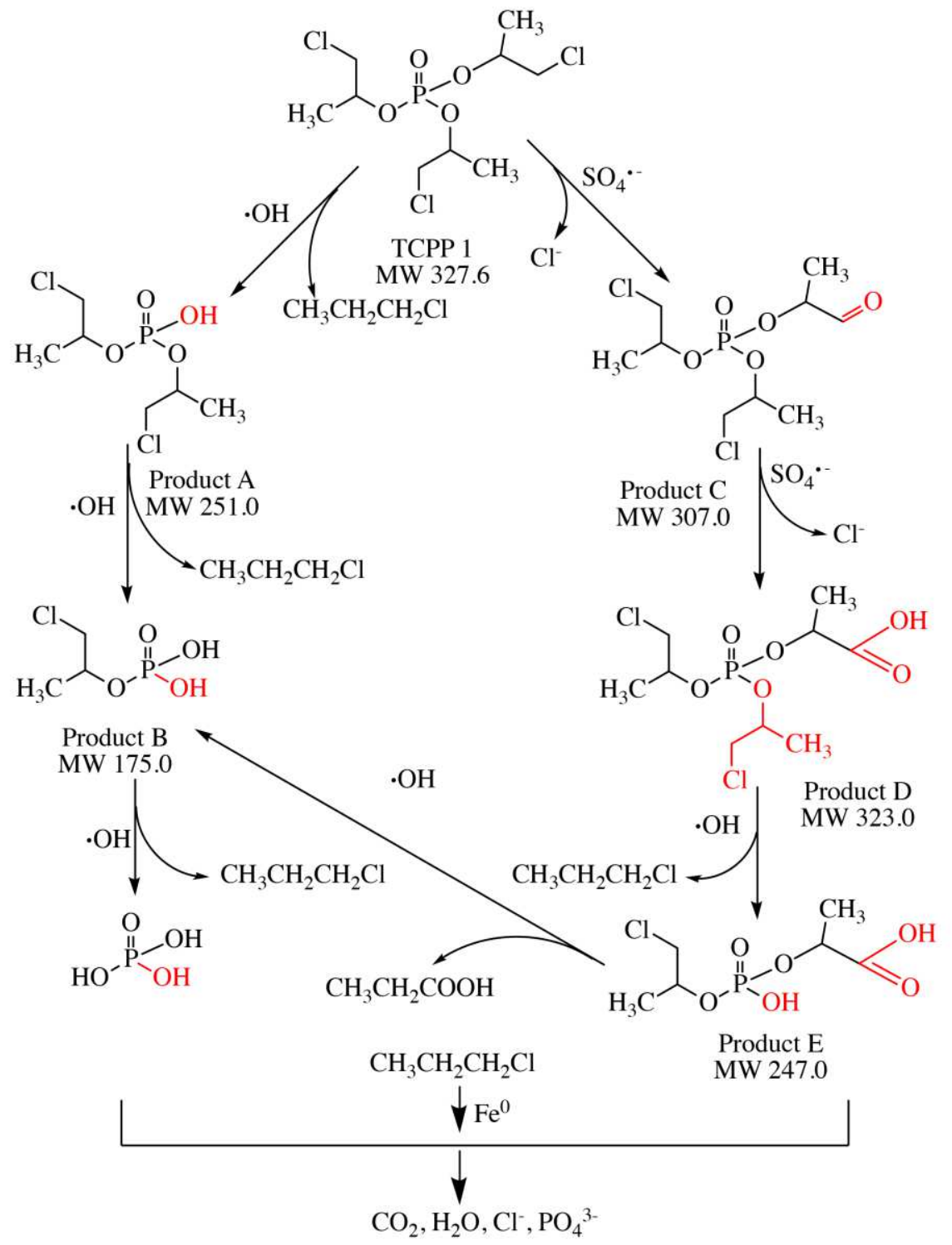

Fig. 5. Proposed degradation pathways of TCPP

390 by $\mathrm{SO}_{4}{ }^{-}$to form a carbonyl compound (product C), which, in turn, is oxidized to

391 produce a carboxylic acid (product $\mathrm{D}$ ). The $\mathrm{C}-\mathrm{Cl}$ bond in product $\mathrm{D}$ cannot be oxidized

392 further, but the phosphate center in product D is attacked by the same route as the first 
394 product $\mathrm{E}$, the $\mathrm{P}-\mathrm{O}-\mathrm{C}$ bonds of which are broken, followed by the formation of 395 propionic acid through substitution, addition and $\mathrm{SO}_{4} \cdot^{-}$cleavage (Yu et al., 2019). The 396 oxidative dechlorination in the second pathway confirms that the role of ZVI is not to 397 reduce TCPP, but to activate persulfate to oxidize TCPP in the $\mathrm{PS}+\mathrm{Fe}^{0}+\mathrm{MC}$ system $(\mathrm{Li}$ 398 et al., 2021).

400 dealkylation. $\cdot \mathrm{OH}$ and $\mathrm{SO}_{4} \cdot{ }^{-}$mainly attack the phosphate center and the $\mathrm{C}-\mathrm{Cl}$ bond at 401 the end of the alkyl chain through substitution, addition and a series of electron transfer 402 reactions. TCPP was converted into $\mathrm{Cl}^{-}, \mathrm{PO}_{4}{ }^{3-}$ and some intermediate products. 403 However, $\mathrm{SO}_{4}{ }^{-}$could not oxidize $\mathrm{C}-\mathrm{Cl}$ bond in micromolecular organochlorides, while 404 ZVI activated by MC could play the role in reductive dichlorination.

405

406 3.6 Toxities of TCPP and its MC degradation intermediates

(a)

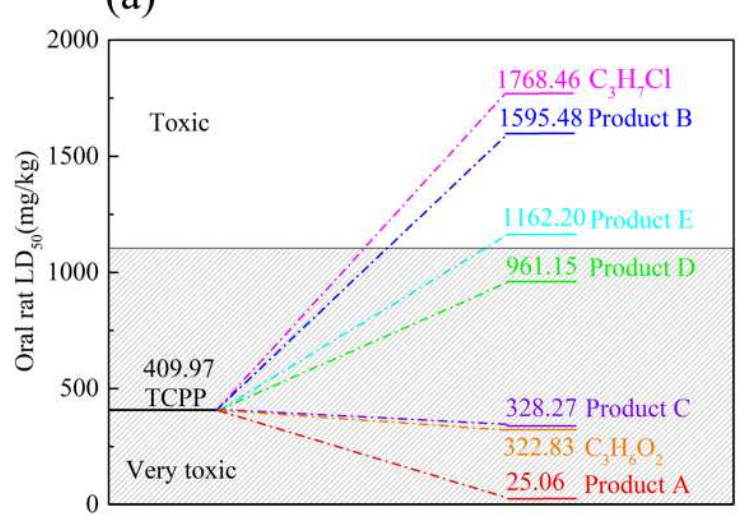

(b)

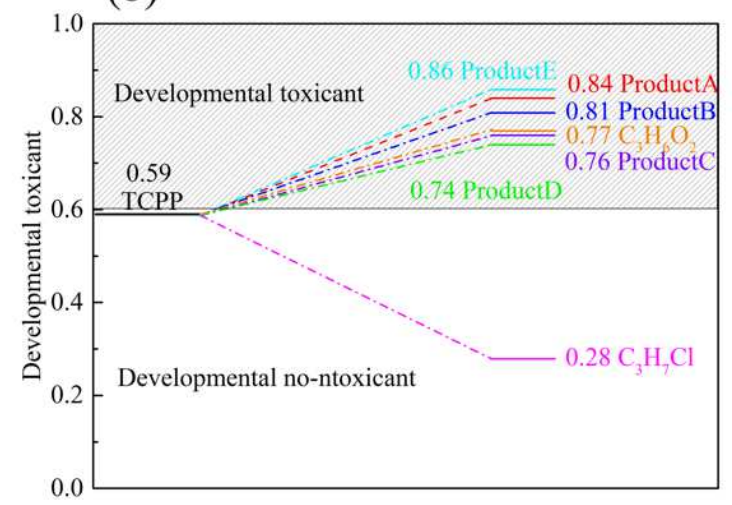


411 version 5.1 was used to evaluate the toxicity of TCPP and its degradation intermediates.

412 In the TEST software, the $50 \%$ lethal dose $\left(\mathrm{LD}_{50}\right)$ of oral rats was selected as an index

413 to predict the acute toxicities of the degraded intermediate products. As shown in Fig.6

414 (a), the $\mathrm{LD}_{50}$ of TCPP was $409.97 \mathrm{mg} / \mathrm{kg}$, which is considered "very toxic". After ball

415 milling, the $\mathrm{LD}_{50}$ values of some intermediates were converted into "toxic" areas, while

416 others still maintained in the "very toxic" areas. The results shows that $\mathrm{PS}+\mathrm{Fe}^{0}+\mathrm{MC}$

417 process reduced the toxicity of $\mathrm{LD}_{50}$, and TCPP can be converted into some low-toxic

418 products.. However, most of intermediates showed developmental toxicant more than

419 that of TCPP (Fig. 6b). Although TCPP could be almost completely degraded via

$420 \mathrm{PS}+\mathrm{Fe}^{0}+\mathrm{MC}$ process, the toxicity of the intermediates did not effectively removed

421 because TCPP could not be completely mineralized by MC. So, the risk resulted from

422 MC degradation of TCPP cannot be ignored.

\subsection{Degradation of TCPP in soils by MC with ZVI and PS}

As shown in Fig. 7, after milling for $2 \mathrm{~h}$, the degradation rates of TCPP 1 in red

426 soil, yellow soil and black soil were $92.13 \%, 85.76 \%$ and $83.83 \%$, respectively, and the

427 degradation rates of TCPP 2 were $90.80 \%, 87.38 \%$ and $87.01 \%$, respectively. To clarify

428 the relation between the degradation rates of TCPP and characteristics of soils, the $\mathrm{pH}$,

429 iron contents and organic matter contents of three soils were detected (Table S2). The

430 results showed that the degradation of TCPP was high under acid conditions. The 
431 previous studies have shown that PS is easily activated to generate $\mathrm{SO}_{4} \cdot{ }^{-}$and $\cdot \mathrm{OH}$ under

432 low $\mathrm{pH}$ conditions, and increasing $\mathrm{pH}$ inhibited the formation of $\mathrm{SO}_{4}{ }^{-}$and $\cdot \mathrm{OH}$. Iron

433 concentration is another important influencing factor (Fan et al., 2018). The degradation

434 of TCPP in red soil was faster than that of the other types of soils because iron

435 concentration in red soil was higher than that of other two soils. The higher the iron

436 concentration in soil, the higher the degradation of TCPP. This is because the presence

437 of iron can promote the production of $\mathrm{SO}_{4}^{-}$. from PS to degrade pollutants rapidly.

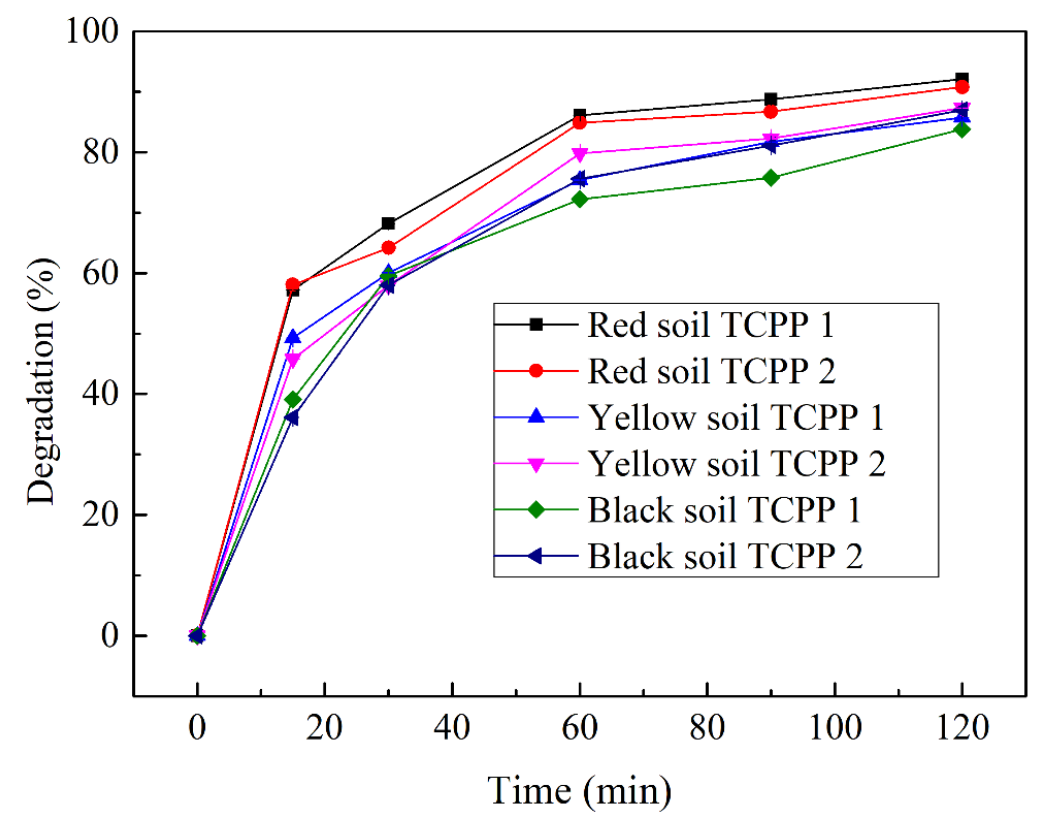

438

439 Fig. 7. Effect of soil types on TCPP degradation. The concentration of TCPP:

$440200 \mathrm{mg} / \mathrm{kg}$; mass ratio of soil to PMS: 18:1; BMR: 30:1; rotation speed: $400 \mathrm{rpm}$

In addition, the order of organic matter contents in different soils were: red soil <

443 yellow soil < black soil. After ball milling for $2 \mathrm{~h}$, the degradation rates of TCPP in the

444 soil were: red soil $>$ yellow soil $>$ black soil. The results showed that the content of 
organic matter in soils affected negatively the degradation rates, which confirmed the

446 previous research (Fan et al., 2018). In addition, during the first 15min of $\mathrm{MC}$

447 degradation, the removal efficiencies of TCPP in soil were higher than that of TCPP

448 without soil mixture, which was because that metal oxide in soil might promote the

449 degradation rates of $\mathrm{MC}$ to TCPP. Therefore, we suppose that $\mathrm{PS}+\mathrm{Fe}^{0}+\mathrm{MC}$ process is a

450 promising method for the removal of organic pollutants in soil.

\section{Conclusions}

This study shows that the $\mathrm{PS}+\mathrm{Fe}^{0}+\mathrm{MC}$ process is an effective method for the degradation of TCPP. The degradation efficiency was as high as $96.5 \%$ after milling for $2 \mathrm{~h}$ with a material ratio of $30: 1$, a BMR of $30: 1$ and a milling speed of $400 \mathrm{rev} \mathrm{min}^{-1}$.

456 The $\cdot \mathrm{OH}$ formed in the combination process attacked the $\mathrm{P}-\mathrm{O}-\mathrm{C}$ bonds in phosphate 457 center of TCPP, meanwhile a $\mathrm{C}-\mathrm{Cl}$ bond in part of the TCPP molecule was oxidized by $458 \mathrm{SO}_{4} \cdot{ }^{-}$to carbonyl and carboxyl groups. resulting in dechlorination via oxidation of the $459 \mathrm{C}-\mathrm{Cl}$ bond. Finally, ZVI reductively dechlorinated the intermediate organochloride 460 products, resulting in the mineralization of TCPP due to the synergistic effect of the 461 reduction of $\mathrm{ZVI}$ and the oxidation reaction of $\cdot \mathrm{OH}$ and $\mathrm{SO}_{4} \cdot^{-}$in $\mathrm{MC}$ process although $462 \mathrm{LD}_{50}$ and developmental toxicant of the intermediate products were not completely 463 removed. These results show that persulfate can be used in the MC degradation of 464 organic pollutants; moreover, pollutants in soils can be degraded via the MC methods. 465 The PS $+\mathrm{Fe}^{0}+\mathrm{MC}$ system is an efficient and environmentally friendly method that is 
466 widely used to remove organic phosphorus pollutants.

468 Author contribution W. Qiao and Q. Yang designed the work, performed MC 469 degradation and sampling, and performed all parameters' measurements used in this 470 project. Y. Qian and Z. Zhang analyzed data and participates in the interpretation of 471 data. W. Qiao and Q. Yang contributed to drafting and critically revising of the paper. 472 All authors gave final approval of the version to be published, and agreed to be 473 accountable for all aspects of the work.

475 Funding This work was financially supported by the Natural Science Foundation of 476 Jiangsu Province (BK20201388), the Industry Prospect and Common Key 477 Technologies in Jiangsu Province (BE2018015) and the Priority Academic Program 478 Development of Jiangsu Higher Education Institutions (PAPD).

480 Availability of data and materials The datasets used or analyzed during the 481 current study are available from the corresponding author on reasonable request.

483 Declarations

484 Ethics approval Not applicable.

485 Consent to participate Not applicable.

486 Consent to Publish Not applicable. 
Competing interests The authors declare no competing interests

488

489

\section{References}

490

491 Abdellaoui M, Gaffet E (1995) The physics of mechanical alloying in a planetary ball mill: Mathematical treatment. Acta Metallurgica et Materialia 43: 339-344

Al-Shamsi MA, Thomson NR (2013) Treatment of organic compounds by activated 494 persulfate using nanoscale zerovalent iron. Industrial Engineering Chemistry Research 52: 13564-13571

496

Björklund J, Isetun S, Nilsson U (2004) Selective determination of organophosphate flame retardants and plasticizers in indoor air by gas chromatography, positive-ion chemical ionization and collision-induced dissociation mass spectrometry. Department of Analytical Chemistry, Stockholm University, S-106 91 Stockholm, Sweden. 18: 3079-3083

Cagnetta G, Huang J, Lu M, Wang B, Wang Y, Deng S, Yu G (2017) Defect engineered oxides for enhanced mechanochemical destruction of halogenated organic pollutants. Chemosphere 184: 879-883

Cagnetta G, Robertson J, Huang J, Zhang K, Yu G (2016) Mechanochemical destruction of halogenated organic pollutants: a critical review. J Hazard Mater 313: 85-102

Cheng Z, Chen Q, Cervantes S, Tang Q, Gao X, Tan Y, Liu S, Ma Y, Shen Z (2020) Two-dimensional and three-dimensional quantitative structure-activity 
Deng S, Bao Y, Cagnetta G, Huang J, Yu G (2020) Mechanochemical degradation of perfluorohexane sulfonate: Synergistic effect of ferrate(VI) and zero-valent iron.

513 Dong Y, Li Y, Zhao C, Feng Y, Dong Y (2019) Mechanism of the rapid mechanochemical degradation of hexachlorobenzene with silicon carbide as an additive. J Hazard Mater 379: 120653

Dubinskaya AM (2010) Transformations of organic compounds under the action of mechanical stress. Russian Chemical Reviews 68: 637-652

518 Fan G, Liu X, Li X, Lin C, He M, Ouyang W (2020) Mechanochemical treatment with CaO-activated PDS of HCB contaminated soils. Chemosphere 257

520 Fan G, Liu X, Lin C, Li PJEC (2018) Peroxymonosulfate assisted mechanochemical Contaminants 4: 22-31

523 Hoffman K, Daniels JL, Stapleton HM (2014) Urinary metabolites of organophosphate 524 flame retardants and their variability in pregnant women. Environ Int 63: 169-172 525 Jurgens SS, Helmus R, Waaijers SL, Uittenbogaard D, Dunnebier D, Vleugel M, Kraak 526 MHS, De Voogt P, Parsons JR (2014) Mineralisation and primary biodegradation 527 of aromatic organophosphorus flame retardants in activated sludge. Chemosphere 528 111: $238-242$ 
Kishi K, Ikeda S (1973) X-Ray photoelectron spectroscopic study for the reaction of evaporated iron with $\mathrm{O}$ and H2O. Bull Chem Soc Jpn 46: 341-345

Li D, Zhong Y, Zhu X, Wang H, Yang W, Deng Y, Huang W, Peng Pa (2021) Reductive degradation of chlorinated organophosphate esters by nanoscale zerovalent iron/cetyltrimethylammonium bromide composites: Reactivity, mechanism and new pathways. Water Res 188

Liu J, Li C, Zhou P, Wu S, Ou H (2017) Heterogeneous photocatalysis of tris(2chloroethyl) phosphate by $\mathrm{UV} / \mathrm{TiO}_{2}$ : Degradation products and impacts on bacterial proteome. Water Res 124: 29-38

Liu X, Zhang X, Shao K, Lin C (2016a) Fe0-activated persulfate-assisted mechanochemical destruction of expired compound sulfamethoxazole tablets. Rsc Advances 6: 20938-20948

Liu X, Zhang X, Zhang K, Qi C (2016b) Sodium persulfate-assisted mechanochemical degradation of tetrabromobisphenol A: efficacy, products and pathway. Chemosphere 150: 551-558

Moulder JF, Chastain J, King RC (1992) Handbook of x-ray photoelectron spectroscopy : a reference book of standard spectra for identification and interpretation of XPS data. Chem Phys Lett 220: 7-10

Oh SY, Kim HW, Park JM, Park HS, Yoon C (2009) Oxidation of polyvinyl alcohol by persulfate activated with heat, $\mathrm{Fe}^{2+}$, and zero-valent iron. J Hazard Mater 168: 346351 
Quintana JB, Rodil R, Reemtsma T, García-López M, Rodríguez I (2008) methodology. TrAC, Trends Anal Chem 27: 904-915

Ruan XC, Ai R, Jin X, Zeng QF, Yang ZY (2013) Photodegradation of tri (2-chloroethyl)

Siow KS, Britcher L, Kumar S, Griesser HJ, Polymers (2014) Deposition and XPS and FTIR analysis of plasma polymer coatings containing phosphorus. Plasma Processes and Polymers 11: 133-141

Sui H, Rong Y, Song J, Zhang D, Li H, Wu P, Shen Y, Huang Y (2017) Mechanochemical destruction of DDTs with Fe-Zn bimetal in a high-energy planetary ball mill. J Hazard Mater 342: 201-209

Un-Jung, Kim, Jung, Keun, Oh, Kurunthachalam, Kannan (2017) Occurrence, removal, and environmental emission of organophosphate flame retardants/plasticizers in a wastewater treatment plant in New York state. Environ Sci Technol 14: 7872-7880

Veen IVD, Boer JD (2012) Phosphorus flame retardants: Properties, production, environmental occurrence, toxicity and analysis. Chemosphere 88: 1119-1153

Wakayama H, Mizuno J, Fukushima Y, Nagano K, Fukunaga T, Mizutani UJC (1999)

568 Wang G, Chen H, Du Z, Li J, Wang Z (2017) In vivo metabolism of organophosphate 569 flame retardants and distribution of their main metabolites in adult zebrafish. Sci Total Environ 590-591: 50-59 
571 Wang N, Lv H, Zhou Y, Zhu L, Tang H (2019) Complete defluorination and 572 mineralization of perfluorooctanoic acid by a mechanochemical method using $573 \quad$ alumina and persulfate. Environ Sci Technol 53: 8302-8313

574 Wang R, Zhu Z, Tan S, Guo J, Xu Z (2020) Mechanochemical degradation of 575 brominated flame retardants in waste printed circuit boards by ball milling. J $576 \quad$ Hazard Mater 385: 121509

577 Wei X, Gao N, Li C, Yang D, Zhou S, Lei L (2016) Zero-valent iron (ZVI) activation 578 of persulfate (PS) for oxidation of bentazon in water. Chem Eng J 285: 660-670

579 Xu W, Mao N, Zhang J (2013) Graphene: a platform for surface - enhanced raman 580 spectroscopy. Small 9: 1206-1224

581 Yan X, Liu X, Qi C, Lin C, Li P, Wang H (2017) Disposal of hexabromocyclododecane 582 (HBCD) by grinding assisted with sodium persulfate. Rsc Advances 7: 23313583 23318

584 Yan X, Liu X, Qi C, Wang D, Lin C (2015) Mechanochemical destruction of a 585 chlorinated polyfluorinated ether sulfonate (F-53B, a PFOS alternative) assisted $586 \quad$ by sodium persulfate. Rsc Advances 5: 85785-85790

587 Yin Z, Han M, Hu Z, Feng L, Liu Y, Du Z, Zhang L (2020) Peroxymonosulfate 588 enhancing visible light photocatalytic degradation of bezafibrate by $\mathrm{Pd} / \mathrm{g}-\mathrm{C} 3 \mathrm{~N} 4$ 589 catalysts: the role of sulfate radicals and hydroxyl radicals. Chem Eng J 390: $590 \quad 124532$

591 Yu X, Yin H, Peng H, Lu G, Dang Z (2019) Degradation mechanism, intermediates and 
592 toxicology assessment of tris-(2-chloroisopropyl) phosphate using ultraviolet $593 \quad$ activated hydrogen peroxide. Chemosphere 241: 124991

594 Zhang W, Huang J, Xu F, Deng S, Zhu W, Yu G (2011) Mechanochemical destruction 595 of pentachloronitrobenzene with reactive iron powder. J Hazard Mater 198: 275$596 \quad 281$

597 Zhang Y, Tao H, Li J, Yang X (2020) Achieving a high-performance P/C anode through 598 P-O-C bond for sodium ion batteries. Ionics 26: 3377-3385

599

600 


\section{Supplementary Files}

This is a list of supplementary files associated with this preprint. Click to download.

- SupplementaryMaterialESPR0528.docx 